\title{
Mitochondrial Superoxide Dismutase Activity in Amyotrophic Lateral Sclerosis
}

\author{
Pilar Larrodé*, ${ }^{*}$, Pedro Iñarrea ${ }^{2}, J_{\text {osé L. Capablo }}^{3}$, Cristina Iñiguez ${ }^{1}$, José R. Ara $^{3}$, Jesús Martin ${ }^{3}$ and \\ Enrique Mostacero ${ }^{1}$
}

${ }^{I}$ Neurology Department, Lozano-Blesa Clinical Hospital, Zaragoza, Spain

${ }^{2}$ Biology Department, Zaragoza University Sciences Faculty, Spain

${ }^{3}$ Neurology Department, Miguel-Servet Hospital, Zaragoza, Spain

\begin{abstract}
Background: Evidence suggests that mitochondrial dysfunction and oxidative stress may be involved in the pathogenesis of Amyotrophic Lateral Sclerosis (ALS). Some studies show the presence of altered anti-oxidative defence enzyme activity in the blood of ALS patients. It has also been demonstrated that a superoxide-dismutase-1 (SOD1) enzyme fraction is located in the mitochondria.

Objective: To Study the correlation between SOD1 activity and clinical data in ALS-patients.

Patients and Methods: SOD1, SOD2 and aconitase activity was analysed in mitochondria of platelets from nine sporadicALS (SALS) patients and nine healthy-controls. The biochemical data was compared and correlated with clinical data from the ALS-patients.

Results: Mitochondrial SOD1 activity was lower in ALS patients than in healthy controls, and much lower in more serious cases of ALS associated with respiratory insufficiency, weight-loss, low scores on the ALSFRS scale and the elderly.

Conclusion: Mitochondrial SOD1 activity may be involved in the clinical evolution of SALS.
\end{abstract}

Keywords: Amyotrophic lateral sclerosis, antioxidant enzymes, mitochondrial dysfunction, oxidative stress, superoxidedismutase.

\section{INTRODUCTION}

Amyotrophic Lateral Sclerosis (ALS) is the most common variant of motor neuron diseases affecting adults. The cause of ALS is not fully understood and several major and not mutually exclusive mechanisms of neurodegeneration may be involved. Only $10 \%$ of cases can be attributed to one specific molecular defect, such as a mutation in the SOD1gene. However, oxidative stress is considered to be the common mechanism causing motor neuron death [1].

Studies of reactive oxygen species (ROS) generation and oxidative protein damage have been reported in both familial (FALS) and sporadic (SALS) forms of the disease [2]. SOD1 is a ubiquitously-expressed antioxidant metalloprotein that catalyzes the dismutation of superoxide to molecular oxygen and hydrogen peroxide. Recent research has demonstrated that a fraction of SOD1 is also located in mitochondria [3]. Mitochondria are the main source of energy and also the major source of ROS, and trigger the intrinsic pathway of apoptotic cell death. Several evidences suggest that mitochondrial dysfunction may be involved in the pathogenesis of ALS by metabolic impairment or by apoptosis [4-6]. However in ALS, oxidative stress and mitochondrial dysfunction may not be restricted only to the nervous system.

*Address correspondence to this author at the Neurology Department, Lozano-Blesa Clínical Hospital, San Juan Bosco Av, $\mathrm{n}^{\mathrm{o}}$ 15, 50,009 Zaragoza, Spain; E-mail: plarrodepellicer@yahoo.es
Some studies suggest the presence of altered antioxidative defence enzymes (ADE) activity in blood samples from ALS patients [7-9].

Our objective has therefore been to assess a possible alteration in mitochondrial ADE activity in blood samples from ALS patients. For this purpose, we determined mitochondrial SOD1 (Cu/Zn-SOD), SOD2 (Mn-SOD), TSOD (SOD1+SOD2) activities, SOD1-presence, and also aconitase activity since it is involved in mitochondrial energy metabolism. This study was carried out on mitochondria obtained from platelets.

A) Sample collection: Blood samples $(50 \mathrm{ml})$ were taken from 9 ALS patients and 9 healthy controls, after obtaining the informed consent. ALS patients were recruited at random, prospectively, within a preliminary study. Inclusion criteria were diagnosis of definiteALS and the exclusion criteria were the presence of other consumptive diseases like cancer, systemic infectious or autoimmune diseases [10-11]. Controls were chosen paired by age and sex.

B) Clinical variables: Clinical variables were recorded, with close attention to those variables relevant to the prognosis (age, time from onset, bulbar or spinal onset) and disease severity criteria, such as respiratory insufficiency (RI: $\mathrm{PaO} 2<60$ and/or $\mathrm{PaCO} 2>50$ $\mathrm{mmHg}$ ), weight loss (body mass index $<18.5$ ), and ALSFRS scale [12-13]. 
C) Biochemical procedures: Platelet-rich plasma was extracted and centrifuged. Washed-platelets were submitted to hypo-osmotic shock, and the mitochondria released were isolated by differential centrifugation [14]. Proteins were determined by Bradfordassay [15]; SOD-activity was analysed as described by Ukeda et al. [16]; and also aconitase activity [17]; Analysis of mitochondrial SOD1-presence and SOD1 electrophoretic migration, under partially denaturing SDS-PAGE conditions, were carried out by westernblot analysis [18]. The COX (Complex IV) subunit $\mathrm{Vb}$ was used as a mitochondrial protein loading control.

D) Statistical Analyses: SPSS 6.1.2 was used to analyse and compare mean enzyme activity levels (MannWhitney test). Enzyme activity levels in ALS patients were analysed for correlation with the clinical variables.

\section{RESULTS}

\section{A) Demographic and Clinical Variables (Table 1)}

There were 9 ALS patients ( 7 male and 2 female) between 33-74 years of age (mean $57.6 \pm 15$ ), and 9 healthy controls ( 7 male and 2 female) between 31-80 years of age (mean $59.2 \pm 16$ ), with no significant difference in the sex and age of the two groups. Two of the ALS patients had the bulbar onset form of the disease and the remainder the spinal onset form. Disease severity: 5 had respiratory insufficiency and 4 weight loss, and the scores on the ALSFRS were between 13-28 points. The time since onset of the disease was between 8-96 months, and 3 patients had died when the study was performed.

\section{B) Enzyme Activities (Table 2).}

Mitochondrial TSOD activity was lower in the 9 ALS patients $(335-554 \mathrm{mU} / \mathrm{mg}$; mean $442 \pm 74)$ than in the 9 healthy controls $(740-995 \mathrm{mU} / \mathrm{mg}$; mean $913 \pm 82)$. The difference was due to a decrease in mitochondrial SOD1 activity with significantly lower values in ALS patients (20$148 \mathrm{mU} / \mathrm{mg}$; mean 81. 52) than in controls (387-500; mean $439 \pm 36 ; \mathrm{p}<0.001, \mathrm{M}-\mathrm{W})$.

Aconitase-activity was lower in the 9 ALS-patients than in the healthy controls but less significant (136-405 mU/mg; mean $269 \pm 124 ; \mathrm{p}<0.05, \mathrm{M}-\mathrm{W})$ and was also related with age $(\mathrm{p}<0.05$, Spearman).

\section{C) SOD1: Western-Blot and Denaturing Electrophoresis}

Despite the differences observed in mitochondrial SOD1 activity between healthy controls and ALS patients, we found no significant difference in the level of SOD1 enzyme presence by western-blot. The COX (Complex IV) subunit $\mathrm{Vb}$. was used as a mitochondrial protein loading control (Fig. 1). In addition, the partially denaturing SDS-PAGE electrophoresis of crude mitochondrial extract in the 9 ALS patients showed that mitochondrial SOD1 retained its association into homodimeric subunits.

\section{D) SOD1 Activity and ALS Severity}

In ALS patients, SOD1 activity was lower in cases 5, 6, 8 and 9, with more than one criterion of severity, such as respiratory insufficiency and weight loss $(20-49 \mathrm{mU} / \mathrm{mg}$; mean 30 $\pm 13 ; \mathrm{p}<0.01, \mathrm{M}-\mathrm{W}$ ) and in patients (cases 5 and 6) with the bulbar onset form of ALS (20-25 mU/mg; mean 22.5 \pm 3.5 ; $p$ $<0.05, \mathrm{M}-\mathrm{W})$. SOD1 activity values correlated with a low score $(<19)$ on the ALSFRS scale in the 9 ALS patients $(20$ $148 \mathrm{mU} / \mathrm{mg}$; mean $81 \pm 52$ and 13-28 ALSFRS; mean $20 \pm$ $6 ; \mathrm{p}<0.05, \mathrm{M}-\mathrm{W})$.

A relationship was also observed with age for aconitase, though less significant $(136-405 \mathrm{mU} / \mathrm{mg}$; mean $269 \pm 124$; $\mathrm{p}<0.05$, Spearman).

\section{DISCUSSION}

A significant decrease in SOD1 activity in mitochondria from ALS-patient platelets was found in this study. As others, we believe that this decrease in mitochondrial SOD1 activity could be involved in the presence of systemic oxida-

Table 1. Demographic and Clinical Variables

\begin{tabular}{|c|c|c|c|c|c|c|c|c|c|c|c|}
\hline $\mathbf{N}^{o}$ & $\operatorname{Sex}^{1}$ & Age, Years & $\mathbf{N}^{\mathbf{o}}$ & $\operatorname{Sex}^{1}$ & $\begin{array}{l}\text { Age, } \\
\text { Years }\end{array}$ & $\begin{array}{c}\text { Time, } \\
\text { Months }\end{array}$ & $\begin{array}{c}\text { Survival, } \\
\text { Months }\end{array}$ & $\begin{array}{l}\text { Onset } \\
\text { Form }\end{array}$ & $\mathbf{R I}^{2}$ & $\begin{array}{c}\text { Weight } \\
\text { Loss }\end{array}$ & ALS FRS $^{3}$ \\
\hline 1 & M & 65 & 1 & M & 60 & 36 & Alive & Spinal & No & No & 28 \\
\hline 2 & M & 47 & 2 & M & 44 & 49 & Alive & Spinal & No & No & 28 \\
\hline 5 & $\mathrm{~F}$ & 69 & 5 & $\mathrm{~F}$ & 71 & 12 & Alive & Bulbar & Yes & Yes & 16 \\
\hline 6 & M & 65 & 6 & M & 64 & 12 & Died, 14 & Bulbar & Yes & Yes & 14 \\
\hline 7 & M & 37 & 7 & M & 37 & 16 & Alive & Spinal & No & No & 28 \\
\hline 8 & M & 65 & 8 & M & 65 & 96 & Alive & Spinal & Yes & Yes & 21 \\
\hline
\end{tabular}


Table 2. Enzymatic Activities

\begin{tabular}{|c|c|c|c|c|c|c|c|c|c|}
\hline \multicolumn{5}{|c|}{ Healthy Controls } & \multicolumn{5}{|c|}{ ALS Patients } \\
\hline $\mathbf{N}^{0}$ & $\begin{array}{c}\text { Aconitase } \\
\mathbf{m U} / \mathbf{m g}\end{array}$ & $\begin{array}{l}\text { SOD1 } \\
\text { mU/mg }\end{array}$ & $\begin{array}{c}\text { SOD2 } \\
\mathrm{mU} / \mathrm{mg}\end{array}$ & $\begin{array}{l}\text { TSOD } \\
\text { mU/mg }\end{array}$ & $\mathbf{N}^{\mathbf{o}}$ & $\begin{array}{c}\text { Aconitase } \\
\mathbf{m U} / \mathbf{m g}\end{array}$ & $\begin{array}{c}\text { SOD1 } \\
\text { mU/mg }\end{array}$ & $\begin{array}{c}\text { SOD2 } \\
\text { mU/mg }\end{array}$ & $\begin{array}{l}\text { TSOD } \\
\mathrm{mU} / \mathrm{mg}\end{array}$ \\
\hline 1 & 535 & 450 & 520 & 970 & 1 & 400 & 135 & 302 & 437 \\
\hline 2 & 216 & 430 & 310 & 740 & 2 & 397 & 148 & 340 & 488 \\
\hline 3 & 260 & 460 & 490 & 950 & 3 & 136 & 85 & 400 & 485 \\
\hline 4 & 413 & 387 & 443 & 830 & 4 & 389 & 123 & 431 & 554 \\
\hline 5 & 355 & 420 & 575 & 995 & 5 & 165 & 25 & 335 & 360 \\
\hline 6 & 420 & 400 & 500 & 900 & 6 & 189 & 20 & 357 & 377 \\
\hline 7 & 535 & 480 & 490 & 970 & 7 & 405 & 120 & 389 & 509 \\
\hline 8 & 650 & 500 & 400 & 900 & 8 & 136 & 49 & 286 & 335 \\
\hline 9 & 205 & 425 & 540 & 965 & 9 & 202 & 25 & 410 & 435 \\
\hline $\begin{array}{l}\mathrm{M} \\
\mathrm{SD}\end{array}$ & $398 \pm 155$ & $439 \pm 36$ & $474 \pm 79$ & $913 \pm 82$ & $\begin{array}{l}\mathrm{M} \\
\mathrm{SD}\end{array}$ & $268 \pm 124$ & $81 \pm 52$ & $361 \pm 49$ & $442 \pm 74$ \\
\hline
\end{tabular}

W-B SOD1-presence in controls and ALS patients
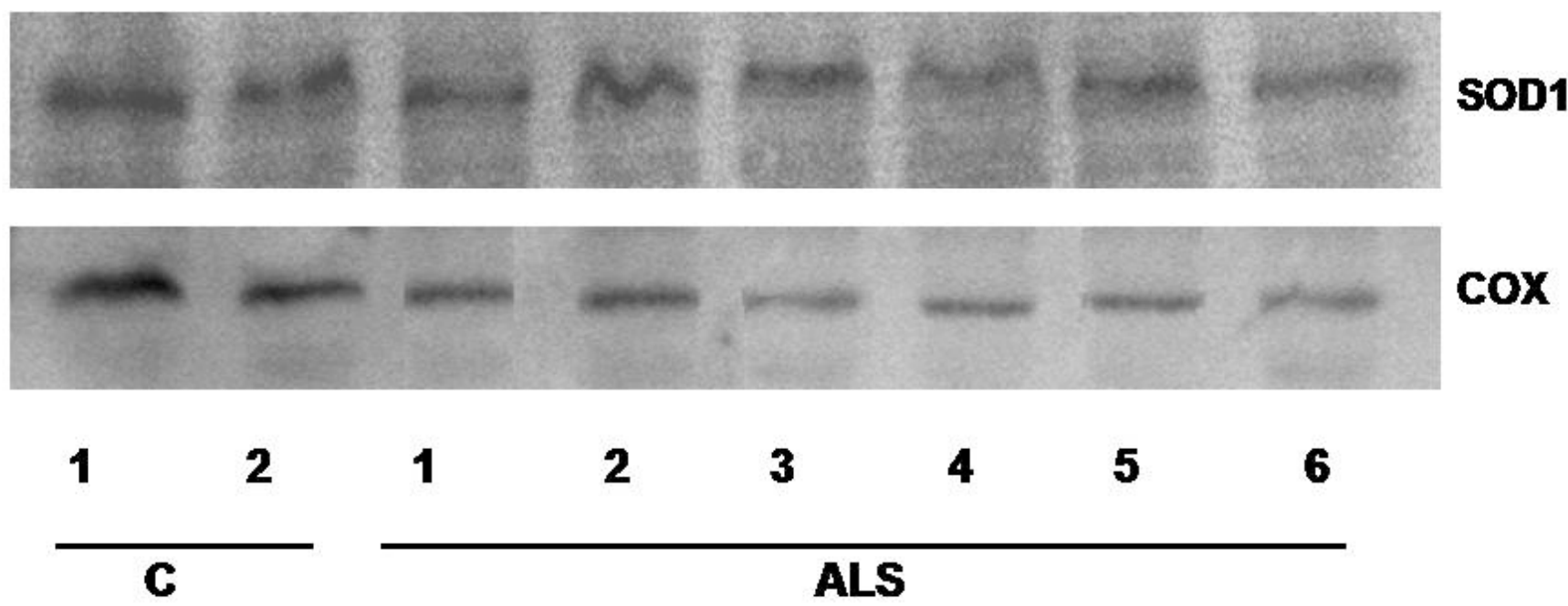

Fig. (1). Healthy controls and ALS patients with lowest activity were chosen. The COX (Complex IV) was used as a mitochondrial protein loading control.

tive stress, affecting the antioxidant enzyme potential of the blood cells [8-9]. This finding could be relevant in the pathogenesis of the disease since it could promote a mitochondrial oxidative stress that would leads to cell death by apoptosis, which is involved in both sporadic and familial ALS [2, 5-6]. SOD1-activity may also decrease due to a critical oxidation of thiol-groups [19]. In this preliminary study, we cannot demonstrate whether this decrease in mitochondrial SOD1 activity in ALS patients is a cause or a consequence of oxidative stress [20-21], nevertheless we believe that it corresponds to the latter since these are patients in terminal clinical situations.

We have also found a correlation between the decrease in SOD1 activity and the severity criteria of ALS (ALSFRS scale, respiratory insufficiency or weight loss), and with age. Some authors also suggest a relationship between the progression rate of ALS and reduced SOD1 activation [22].
Others consider the existence of chronic hypermetabolism in ALS occurring in parallel with a decrease in free fat mass, and both hypoxaemia and weight loss may increase oxidative pressure as the disease progresses [23]. Like other authors, we believe that narrow concept of ALS as a selective motor neuron disease is developing into a more general concept, in which this disease might be considered a multisystem disorder with selective vulnerability of motor neurons [24].

\section{REFERENCES}

[1] Agar J, Durham H. Relevance of oxidative injury in the pathogenesis of motor neuron diseases. Amyotroph Lateral Scler Other Motor Neuron Disord 2003; 4: 232-42.

[2] Ferrante RJ, Browne SE, Shinobu LA, et al. Evidence of increased oxidative damage in both sporadic and familial amyotrophic lateral sclerosis. J Neurochem 1997; 69: 2064-74.

[3] Okado-Matsumoto A, Fridovich I. Subcellular distribution of superoxide dismutases (SOD) in rat liver: $\mathrm{Cu}, \mathrm{Zn}-\mathrm{SOD}$ in mitochondria. J Biol Chem 2001; 276: 38388-93. 
[4] Hervias I, Beal MF, Manfredi G. Mitochondrial dysfunction and amyotrophic lateral sclerosis. Muscle Nerve 2006; 33: 598-608.

[5] Borthwick GM, Jonson MA, Ince PG, Shaw PJ, Turnbull DM. Mitochondrial enzyme activity in amyotrophic lateral sclerosis: implications for the role of mitochondria in neuronal cell death. Ann Neurol 1999; 46: 787-90.

[6] Bowling AC, Schulz JB, Brown RH, Beal MF. Superoxide dismutase activity, oxidative damage and mitochondrial energy metabolism in familial and sporadic amyotrophic lateral sclerosis. J Neurochem 1993; 61: 2322-5.

[7] Bonnefont-Rousselot D, Lacomblez L, Jaudon M, et al. Blood oxidative stress in amyotrophic lateral sclerosis. J Neurol Sci 2000; 178: 57-72.

[8] Cohen O, Kohen R, Lavon E, Abramsky O, Steiner I. Serum Cu/Zn superoxide dismutase activity is reduced in sporadic amyotrophic lateral sclerosis patients: J Neurol Sci 1996; 143: 118-20.

[9] Nikolic-Kokic A, Stevic Z, Blagojevic D, et al. Alterations in antioxidative defence enzymes in erythrocytes from sporadic amyotrophic lateral sclerosis (SALS) and familial ALS patients. Clin Chem Lab Med 2006; 44: 589-93.

[10] Andersen PM, Borasio GD, Dengler R, et al. EFNS Task Force on management of amyotrophic lateral sclerosis: guidelines for diagnosing and clinical care of patients and relatives. Eur $\mathrm{J}$ Neurol 2005; 12 (12): 921-38.

[11] Brooks BR. El Escorial World Federation of Neurology criteria for the diagnosis of amyotrophic lateral sclerosis. J Neurol Sci 1994; 124: 96-107.

[12] Kaufmann P, Levy G, Thomson JL, et al. The ALS-FRS predicts survival time in an ALS clinic population. Neurology 2005; 64: 3843.

[13] Magnus T, Beck M, Giess R, et al. Disease progression in amyotrophic lateral sclerosis: predictors of survival. Muscle Nerve 2002; 25: 709-14.

[14] Ti F, Lenaz G. Isolation and subfractionation of mitochondria from animal cells and tissue culture lines. Methods Cell Biol 2001; 65: $1-35$.
[15] Bradford, MM. A rapid and sensitive for the quantitation of microgram quantitites of protein utilizing the principle of protein-dye binding. Anal Biochem 1976; 72: 248-54.

[16] Ukeda H, Maeda S, Ishii T, Sawamura M. Spectrophotometric assay for superoxide dismutase based on tetrazolium salt 3'--1-(phenylamino)-carbonyl--3,4-tetrazolium]-bis (4-methoxy-6-nitro) benzenesulfonic acid hydrate reduction by xanthine-xanthine oxidase. Anal Biochem 1997; 251: 206-9.

[17] Drapier JC and Hibbs JB. Aconitases: a class of metalloproteins highly sensitive to nitric oxide synthesis. Methods Enzymol 1996; 269: $26-36$

[18] Tiwari A, Hayward LJ. Familial Amyotrophic Lateral Sclerosis Mutants of Copper/Zinc Superoxide Dismutase Are Susceptible to Disulfide Reduction. J Biol Chem 2003; 278: 5984 -92.

[19] Rakhit R, Crow JP, Lepock JR, et al. Monomeric $\mathrm{Cu}, \mathrm{Zn}-$ superoxide dismutase is a common misfolding intermediate in the oxidation models of sporadic and familial amyotrophic lateral sclerosis. J Biol Chem 2004; 279: 15499-504.

[20] Bacman SR, Bradley WG, Moraes CT. Mitochondrial involvement in amyotrophic lateral sclerosis: trigger or target? Mol Neurobiol 2006; 33: 113-31.

[21] Rizzardini M, Mangolini A, Lupi M, et al. Low levels of ALSlinked $\mathrm{Cu} / \mathrm{Zn}$ superoxide dismutase increase the production of reactive oxygen species and cause mitochondrial damage and death in motor neuron-like cells. J Neurol Sci 2005; 232: 95-103.

[22] Völkel H, Selze M, Walk T, et al. Reduced reactivation rate in mutant CuZnSOD and progression rate of amyotrophic lateral sclerosis. Eur J Neurol 2004; 11(6): 397-404.

[23] Desport JC, Torny F, Lacoste M, Preux PM, Couratier P. Hypermetabolism in ALS: correlations with clinical and paraclinical parameters. Neurodegener Dis 2005; 2: 202-7.

[24] Dupuis L, Oudart H, René F, Gonzalez de Aguilar JL, Loeffler JP. Evidence for defective energy homeostasis in amyotrophic lateral sclerosis: Benefit of a high-energy diet in a transgenic mouse model. Proc Natl Acad Sci USA 2004; 101(30): 11159-64.

(C) Larrodé et al.; Licensee Bentham Open.

This is an open access article licensed under the terms of the Creative Commons Attribution Non-Commercial License (http: //creativecommons.org/licenses/by-nc/ 3.0/) which permits unrestricted, non-commercial use, distribution and reproduction in any medium, provided the work is properly cited. 